\title{
Utilizing Linguistic Resources in the Analysis of Poetry
}

\author{
Dr. Mukhalad Malik \\ Department of EnglishCihan University/ Sulaimaniya
}

\begin{abstract}
The major aim of the current paper is to investigate the probabilities of utilizing language based approach in the analysis of literature, specifically, poetry. The study in particular focuses on how certain linguistic resources can be utilized to analyse poetry in terms of explaining some selected lines of specific poems; that is, a language based approach to the analysis of poetry. This is done throughout the entire paper by applying specific linguistic resources including lexical, syntactic and phonological analyses. The article explicitly reveals that utilizing such resources in the analysis of poetry plays a significant role in understanding and conveying the intended message. Such analysis is definitely useful for a better and more comprehensive interpretation of various lines in various poems. This method is worth consideration because it is based on a linguistic analysis of literature.
\end{abstract}

Key words: utilizing, linguistic resources, literary analysis, interpretations, meanings

\section{INTRODUCTION}

There have been many attempts to approach literature on the basis of a linguistically oriented study. However, very little attention is given to the linguistic resources that might be utilized in literary analysis as far as the implications of these studies are concerned. The process of handling literary texts has been largely incomplete; language items which compose the literary text (including poetry) are studied in details but in separation and almost no attempt is made to connect them to other aspects of language use in the same text so as to understand the exact interpretation and meaning. The present work explores the possibilities of adopting a language based approach to the analysis of literature, specifically, poetry in English language. In fact the analysis of a literary work can no longer be treated as a matter of personal insight and understanding alone. Literary analysis can make use of the knowledge of linguistics resources in exploring various related aspects to the interpretations and meanings of poems. The present study is confined to applying syntactic, lexical and phonological levels of linguistics in the analysis of poetry with reference to some poems so as to understand practically how such resources can be applied.

\section{UTILIZING LINGUISTIC RESOURCES IN POETRY}

In fact, it is very significant to understand why utilizing linguistic resources in the analysis of poetry are so crucial and important. There has been an urgent need to re-examine the traditional approach to the literature analysis which has relied on literary aspects only ignoring significant features of language aspects when trying to interpret or understand the meaning of various poems. Traditionally, literary analysis includes an introduction to the text, the writer's attitude then dealing with the text in detail focusing on its themes and the significant poetic devices like similies or metaphors used in the poem. (Yadugiri, 1992). But indeed, utilizing various linguistic resources would offer insights and closer looks at those aspects of language use in a text which plays a significant role in conveying meanings and are therefore useful for the interpretation of the text. Halliday et al. (1964: 184-185) show the importance of utilizing linguistic resources in the analysis of poetry when they state that "no student should be pushed into literary work until he has a sufficient linguistic ability to understand, enjoy and appreciate the literary texts that he will be studying." The importance of language based approach to the analysis of literature is explicitly stated by Yadugiri (1992: 71) when he says that "It is misleading in teaching a literary text communicatively to focus on a part of the text in isolation. We have, therefore, to consider the text in its entirety." There are also foundations to believe that a linguistically oriented approach is expected to analyse the form and discover the poetic meaning and the effect of linguistic structures (Sharma, 1988). The analysis of a poem, therefore, can offer certain instructive advantages and essentially involves linguistic analysis of a certain kind. This kind of analysis is intended for a better interpretation and can lead to a deeper understanding of a literary work as far as the meaning and other related aspects are concerned. After identifying the importance of language based approach in analysing poetry, the crucial question to be posited is: How can linguistic resources be practically utilized in the analysis of various poems? Taking into consideration one significant point in the interpretation of poems and understanding their meanings, it is possible to note that

DOI: $10.9790 / 0837-2203067376 \quad$ www.iosrjournals.org $\quad 73 \mid$ Page


titles have different meanings based on grammatical distinctions and raise different perceptual images when attempting to explain them (Sharma, 1982). The title, therefore, is of prime importance; "Once the title is revealed, the poem regains its coherence and beauty." (Boulton, 1979:107). Other considerations of utilizing linguistic resources can certainly examine the entire poem. For instance, the first sentence of the poem follows the title so it can be taken as a unit because it initiates the poetic discourse and is an important pointer to the general possible interpretation and meaning of the entire poem. It is closely linked with the rest of the poem and can be modified by what follows. It may or may not be tied to the title by linguistic cohesion (Sharma, 1988). The plural form, for example, gives a concrete meaning; a modifier may be described in concrete terms. When discussing other linguistic resources such as semantics, it can be clearly observed that, for instance, connotations have to be realized as well as the suggestive meaning. Moreover, types of sentences have their significance in literature. A change of sentence type from declarative, for example, to imperative makes an important turn. The linguistic configuration of a poem helps discover the total effect of the poem along certain dimensions: concrete-abstract, general-specific, dynamic-static, sensuous-conceptual; they also lead to a linguistic recognition of the linguistic patterning of the poem (ibid). The declarative sentence, for example, has an informative function: it states something; the imperative is associated with resolutions and power. What can be noticed is that an entire interpretation and understanding of meaning and, hence, an entire appreciation of the poem can take the form of a group discussion on vocabulary, types of sentences, structures and so on.Going through deeper details of analysis, it also possible to involve sound patterns used in various poems which largely contribute to the meaning of the poem. "The sound patterns used in the poem go without the patterns of meaning and set up new relations between certain sets of words like mountain and fountain. Sounds are meaningful and the recognition of these patterns in a poem is as crucial to its interpretation as the recognition of grammatical structures or meaning." (Yadugiri, 1992: 80-81). A concern with the investigation and significance of utilizing linguistic resources within and across texts including poetry is currently vital to many quite different areas of linguistics, including Critical Discourse Analysis (e.g. Fairclough 1992) and Corpus Linguistics (e.g. Biber 1988).

\section{LINGUISTIC ANALYSIS}

When approaching the analysis of poetry relying on linguistic analysis, it might be significant to do so in terms of Halliday's "Systemic Linguistics". Such analysis would definitely exemplify the language system i.e. paradigmatically related (semantic, syntactic and phonological) categories. Consequently, the linguistic resources that are relied on comprise lexical analysis (which is the core of semantic study), syntactic analysis and metrical which is part of the phonological aspect of language (Halliday, 1964).

\subsection{Lexical Analysis}

Utilizing this linguistic resource is very important in the analysis of poetry as it can show an efficient interpretation of the poem and, thus, arriving at the possible general meaning. The lexical analysis comprises the demonstration of the words chosen in a poem and by showing their type and analyse them lexically, the interpretation will be clear to a certain extent and understanding the general meaning will be efficiently achieved. The lexical units are simple, compound and complex and as such, there should be a consideration of the nature of the lexical item, its collocational span, its scatter and its membership in the set. When analysing a poem on the basis of lexical analysis, it is possible to show that the occurrences and repetitions of certain words may produce a specific effect. This includes all sorts of context i.e. potential, actual, denotative, connotative and so on. In the poem "The Hollow Men" by Eliot (1964), there are content and function words. The lexical analysis of this poem further shows that the occurrence of nouns is more than occurrence of other lexical categories such as adverbs and verbs. Such analysis reveals the fact that the poem is directed towards a "noun" rather than an action because the hollow men are paralyzed.

On the other hand, the use of function words is related to the interpretation of theme of the poem because the life of the hollow men is worthless and it is devoid of real existence. This further illustrates the meaning of the poem by referring to the fact that some nominal element and its description constitute the theme of the poem. Concerning the use of the nominals (which has the highest percentage in the poem), the connotative reference shows that they are abstract and this fact helps to draw a further interpretation that an existential state of affairs is the main concern of the poet. There are also numerous lexical sets such as "hollow", "stuffed", "straw", "dry voices", "whisper", "quiet and meaningless", "dry grass", 'broken Glass", and "dry cellar", all of which are related to the very opening meaning that the poem is about. On the basis of such analysis, it is possible to state the fact the use of a particular category of lexis has foregrounded the notion of the plainness of the modern world in the poem. It is clear that the lexical sets connote the central message of the poem.

To emphasise the importance of the lexical analysis, it is possible to consider another poem to evaluate this kind of analysis. In the poem "Poet for Our Times" by Duffy (1994), the lexical analysis plays a significant 
role in arriving at the possible interpretation and meaning of the poem. In this poem, the lexical analysis reveals that it contains a plenty of colloquial expressions: "just a knack", "Just bang the words down", "grab attention" , "as punters rush on by", "the buggers", "you got" and so on. In some cases the lexical items involved have very wide and general currency in British English, such as "the box" for "television" and "kids" for "children". In other cases, they are more constrained: "punters" is often connected to gamblers/betters, but it can also be applied to the anonymous public one is trying to attract, including the readers of newspapers; "buggers," on the other hand, is a (relatively mild) swearword, which in this case is used in reference to the letters making up the headlines themselves. In addition, the use of "I like", "I like" and "I've got" illustrates the main speaker's expressed views about the nature of the work and its relationship with verbal art which give rise to the kind of phenomena that Bakhtin captures by means of the notion of "internal dialogism" (Bakhtin 1981: 276).

The main speaker's claims can be seen as part of a debate about the nature of poetry, and, more specifically, about the distinction between varieties that are perceived as non-literary, popular and low in prestige.

\subsection{Syntactic Analysis}

The syntactic analysis (including some grammatical aspects) is of great importance to both the interpretation and understanding the general meanings of poems. In " The Hollow Men", the use of the determiner "the" in the title of the poem with a plural common noun "men" may have the interpretation that the poet's meaning in this respect is to talk about the 'hollowness" of the contemporary man. It refers to the wastelanders of current time and is an important linguistic signal to the meaning of the poem. The syntactic analysis reveals a few instances of syntactic regularity which foreground the meaning of the poem as in: "Shape without form, shade without colour, Paralysed force, gesture without motion." With such syntactic patterns, the use of negation is intended to show the contradictions in which the wastelanders are fastened to. The syntactic regularity in the last section of the poem "This is the way the world ends", "This is the way the world ends" depicts the predicament of the hollow men-"between idea and reality;" "between motion and act", 'between emotion and response" falls the shadow. The same syntactic patterning can be found in "Poet for Our Times" where the poetess uses the syntactic pattern $S V$ in many instances as in "I write", "I've made", "I like, "I've got", "I show" and "I wish". The use of such regular syntactic patterns can be interpreted as an attempt to show the personal experience that the poetess is after and, thus, the meaning might be attributed on the basis of the use of this structure. Other syntactic patterns used in both poems which are clearly noticeable is the repetition of certain used structures such as complete sentences, phrases and words. Such linguistic resource may largely contribute in an efficient interpretation and, once again, a general clear meaning would be achieved. In Eliot's poem, the syntactic similarity is found in lines such as "we are the hollow men", "we are the stuffed men", "Here we go around the prickly pear", "prickly pear", "prickly pear", "Here we go around the prickly pear". The similarity is a syntactic repletion-an important poetic device to pack the poem with meaning- where the repetition reflects the sense of the poem. This linguistic resource is entirely utilized to strengthen the meaning of the pointlessness of human actions in the modern world. Still the most important example of such type of syntactic repetition is the last lines of the poem in which the sentence "This is the way the world ends" is repeated three times. This repetition reinforces the poet's distrust and reflects the overall depressing and tragic tone of the poem. Similarly, the repetition of the use of the vocative pronoun "I" in Duffy's poem reflect the fact that the meaning is intended to express personal attitude and, hence, the focus is almost exclusive on the speaker to draw the attention to personal insights. The repetition of the contraction as in "it's just", "one's born with", "you've got", "they're", I've made" and other instances show that this grammatical aspect of language is utilized to refer to the idea that such use is usually associated with everyday common interaction and the use of such contractions are characteristic of informal speech, where they exploit the widespread ground and familiarity shared by interactants and have the function of saving speakers' effort in the production of utterances.

\subsection{Phonological Analysis}

Though this linguistic resource might not contribute largely to the interpretation and the meaning of the poem, it is worth considering in specific instance. From a metrical view, "The Hollow Men" can be identified as having free verse and a falling intonation. This might reflect to a certain extent the misery and sadness of the hollow men. What can be noticed is the fact that the poem has no fixed syllables; the number of syllables varies from a line to another and that's why the poem does not have any fixed rhythm. Using various syllables as a linguistic resource is utilized, seemingly, to reflect the disappointment and emptiness of the hollow men. The use of monosyllables is the main feature of this poem and thus, the use of monosyllabic words is simple and so as the general meaning of the poem which is crammed with ideas. On the other hand, Duffy's poem has alternative rhyming stanzas which emphasize the fact that there is a clear fixed rhythm. The rising intonation which the poem is filled with might reflect the strength of the proposed ideas and that the speaker of the poem is a person with confidence and well-sighted. The easy rhythm and casual, conversational tone of the poem might reflect the idea that any straight attempt or scrupulous thought has disappeared.

$\begin{array}{lll}\text { DOI: 10.9790/0837-2203067376 } & \text { www.iosrjournals.org } & \text { 75|Page }\end{array}$




\section{IV.}

\section{CONCLUSION}

Utilizing linguistic resources in the analysis of poetry is one of the most important approaches that must be considered. It is mainly directed to achieve a better and a more efficient approach to the study of poetry. Focusing on linguistic resources such as the lexicon, syntactic structures and phonology when analysing a poem might assist a lot in understanding how writers express their ideas and what meanings they intend to convey. The linguistic resources are, in fact, typical tools for the analysis of the use of language, and since poetry is concerned with language use, although poetically, those resources can be applied to show in detail possible interpretation which would ultimately result into an efficient understanding of the meaning of a certain poem. Such analysis should be systematic and should focus on certain aspects of language that contribute largely in a successful and reliable analysis.

\section{BIBLIOGRAPHY}

[1] Bakhtin, Mikhail. 1981. The Dialogic Imagination: Four Essays. Ed. by M Holquist, transl. by C. Emerson and M. Holquist. Austin, Texas: University of Texas Press.

[2] Biber, Douglas.1988. Variation across speech and writing. Cambridge: Cambridge University Press.

[3] Boulton, M.1979. The Anatomy of Poetry. New Delhi: Kalyani Publishers.

[4] Duffy, Carol Ann.1994. Selected Poems. London: Penguin.

[5] Eliot, T. S.1963. Collected Poems. GB.: Faber and Faber Ltd..

[6] Fairclough, Norman.1992. Discourse and Social Change. Cambridge: Polity Press.

[7] Halliday, M. A. K. and A. McIntosh.1964. The Linguistic Sciences and Language Teaching. London: ELBS

[8] Sharma, R. S. 1988. Teaching Poetry: A Linguistic Method in New Directions in English Language Teaching. New Delhi: Pointer Publishers.

[9] Yadugiri, M. A. 1992. "The Teaching of Literature”. In Indian Journal of Applied Linguistics. Vol.XVIII, No.I, June. 